\title{
Modelling the characteristics of axial compressor of variable flow passage geometry, working in the gas turbine engine system
}

\author{
Paweł Wirkowski \\ Polish Naval University
}

\begin{abstract}
This paper concerns application of mathematical modelling methods to analyzing gas-dynamic processes in marine gas turbines. Influence of geometry changes in axial compressor flow passage on kinematical air flow characteristics, are presented. The elaborated mathematical model will make it possible to realize - in the future - simulative investigations of gas-dynamic processes taking place in a compressor fitted with controllable guide vanes.
\end{abstract}

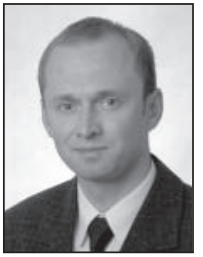

Keywords : marine gas turbine engine, compressor, modelling of characteristics.

\section{INTRODUCTION}

An important problem of operation of ship gas turbine engines ${ }^{1}$ is to know influence of changeable technical state of engine on its working parameters. Compressor is a unit of gas turbine engine especially sensitive on changes in its technical state during operation $[5,6]$. The more-or-less-contaminated atmospheric air flowing into the compressor causes a.o. continuously changing form of blade passages, increased roughness of blade surfaces as well as change of mass of compressor rotor. It seriously impacts compressor's operation stability, changes its characteristics as well as performance and efficiency of the entire engine. If the compressor design contains a control system for setting controllable blades of guide vanes (of initial swirl guide vane or/and first stage guide vanes) to make cooperation of all engine's units optimal by continuous correcting the compressor characteristics then the disturbances occurring in work of the system will result in changes in operation of the compressor and engine, of a character similar to those due to rotational speed changes or contaminated blade passages of compressor.

Individual parametric features of every engine in service are identified by using expensive experimental tests conditioned by many constructional and operational limitations. Dynamic development of computer technique applied already to the design stage of engine's units has made it possible to use it also for numerical simulation of changeable technical state processes. Such approach greatly shortens the time necessary for diagnostic tests aimed at determining a set of „,defectsymptom" relations, as compared with the time-consuming and expensive investigations carried out on real objects. Having at one's disposal an appropriate computer software one is able to elaborate the models simulating operation of engine's units, verified within an allowable range of static and dynamic loads. The computer software based on mathematical models makes it possible to realize numerical experiments consisting in putting-in real variables and hypothetical technical states of engine.

\section{CHARACTERISTICS OF AXIAL COMPRESSORS WORKING IN ENGINE SYSTEMS}

The universal characteristics of compressor (Fig.1), showing the dependence of the compression $\pi_{\mathrm{s}}$ and efficiency $\eta_{\mathrm{s}}$ of compressor on the air mass flowing through it, $\dot{\mathrm{m}}$, and the rotational speed $n$, make it possible to determine the most favourable conditions of co-operation of the compressor with other units of the engine under assumption that parameters of the sucked -in air are of the values complying with the so-called ISA standard atmosphere $\left(\mathrm{p}_{\mathrm{ot}}=1.013\right.$ bar, $\mathrm{T}_{\mathrm{ot}}=273.15 \mathrm{~K}$, $\varphi=0 \%$ ). The characteristics serve for the selection of optimum conditions for air flow control and assessment of influence of operational factors on parameters of the compressor.

Fig. 2 highlights occurrence of unstable work phenomenon, on which a schematic diagram is presented of flow round a blade of axial stage rotor under motion with the constant rotational speed $n$, for which a change in the air flow rate $\dot{m}$ is effected. Fig.2a shows the schematic diagram of the flow in the conditions for which the air flow rate corresponds with optimum efficiency of the stage.

The relative velocity vectors $\mathrm{w}_{1}, \mathrm{w}_{2}$ are parallel to camber line of blade profile, that is conductive to laminar flow through blade passages. The lowering of air flow (Fig.2b) as compared with calculation conditions at the circumferential velocity $\mathbf{u}$ maintained constant, makes the axial component of absolute

${ }^{1}$ Called also further : ,engines” 
velocity, c , smaller, that results in the increasing of the inlet angle $\mathbf{i}$ of air flow onto rotor blades. It is conductive to boundary layer separation out of concave surfaces of blades and to generation of whirl zones.

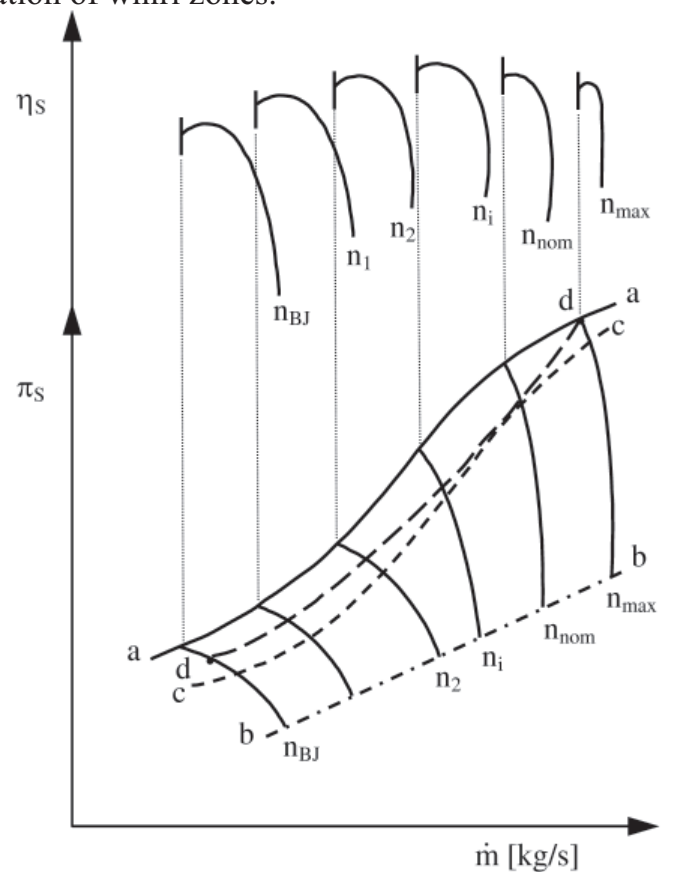

Fig. 1. Characteristics of axial compressor of gas turbine engine; $\boldsymbol{a}-\boldsymbol{a}$-stable operation limit, $\boldsymbol{b}$-b-limit of maximum air flow rates, $\boldsymbol{c}-\boldsymbol{c}$ - line of optimum values of compressor efficiency, $\boldsymbol{d}$-d - line of compressor-turbine co-operation

A similar phenomenon occurs on convex surface of blade (Fig.2c) when air flow rate becomes greater at the circumferential velocity maintained constant. Then the air flow rate $\dot{m}$ takes its maximum values.

At critical values of angles of flow through the produced whirl zones which constitute circumferentially displacing low-pressure zones, a sudden air flow reversal (pumping) towards compressor's inlet can happen, that results in violent flow pulsations transferred onto engine's structure. The phenomenon is detrimental and dangerous because of thermal

a)

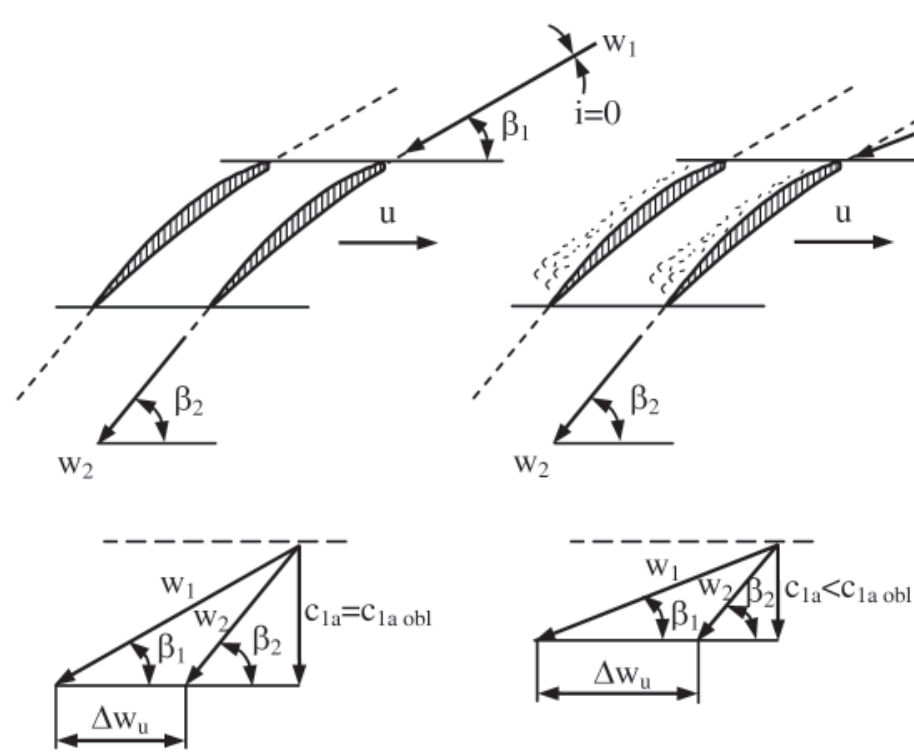

and mechanical overload of engine's structure. The occurring vibrations of significant amplitudes may cause fatigue cracks in blades $[1,2,4]$.

In this connection the compressor should be - within the range of service rotational speeds - so adjusted as to place the line of compressor-network co-operation with certain stable work margin $[5,6,9]$.

During engine's operation, rotational speed of rotor, air flow rate and optimum form of kinematics of air flow through stage blade passages, determined by the air flow inlet angle $\mathbf{i}$ onto the blades, have the greatest impact on compressor's performance and efficiency. The main principle of compressor control during changing its rotational speed or flow rate is to maintain values of the air flow inlet angles $\mathbf{i}$ close to zero. One of the used methods for control of axial compressor is to change geometry of its flow passage by applying a controllable inlet guide vane or controllable guide vanes of a few first stages of compression [4].

\section{CONTROLLABLE INLET GUIDE VANE}

The application of controllable blades of inlet guide vane and guide vanes of particular compressor's stages makes it possible to simultaneously change inlet angles of flow onto blades of rotor rings of the stages by changing the setting angles of the blades of the guide vanes during compressor's rotational speed changing. Fig.3 shows the essence of control of blades of controllable guide vanes by using single compression stage as an example. The situation shown in Fig.3b where velocity directions and values are indexed "1", corresponds with average values of rotational speed service range of compressor's rotor. In this case takes place an average angular setting of blades of guide vane ring, at which the inlet angle of flow onto blades of rotor ring does not generate disturbances in the flow through blade passages. In the case of smaller values of rotational speed of compressor, i.e. appearance of a smaller value of the axial component of absolute velocity, $\mathrm{c}_{1}$, , it is necessary to decrease the outlet angle of flow from the controllable blades of the guide vane ring (Fig.3a) to such an extent as to maintain the same value of inlet angle of flow onto rotor blades. The analogous situation takes place during operation of compressor at greater values of rotational speed of rotor, for which the axial b)

c)
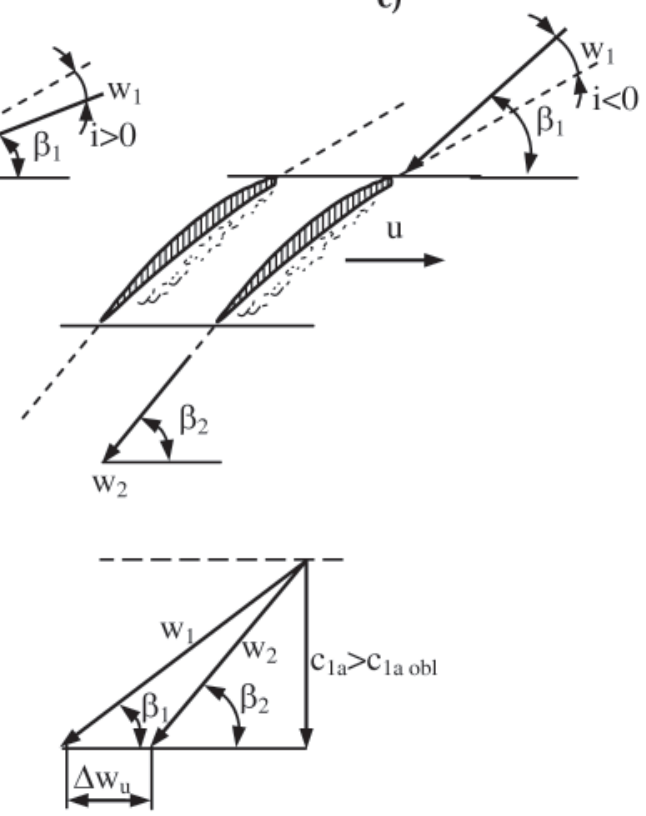

Fig. 2. Schematic diagram of flow round blades of compressor axial stage ring at constant rotational speed of the rotor and changeable angles of air flow inlet. a) calculation angle of air flow inlet, b) positive angle of air flow inlet of, c) negative angle of air flow inlet. 
component value of absolute velocity, $\mathrm{c}_{1 \mathrm{a}}$ ", increases. Then it is necessary to increase the outlet angle of flow from guide vane blades, Fig.3c, to maintain stable work of compressor hence a constant value of inlet angle of flow onto rotor blades.

a)

b)

c)

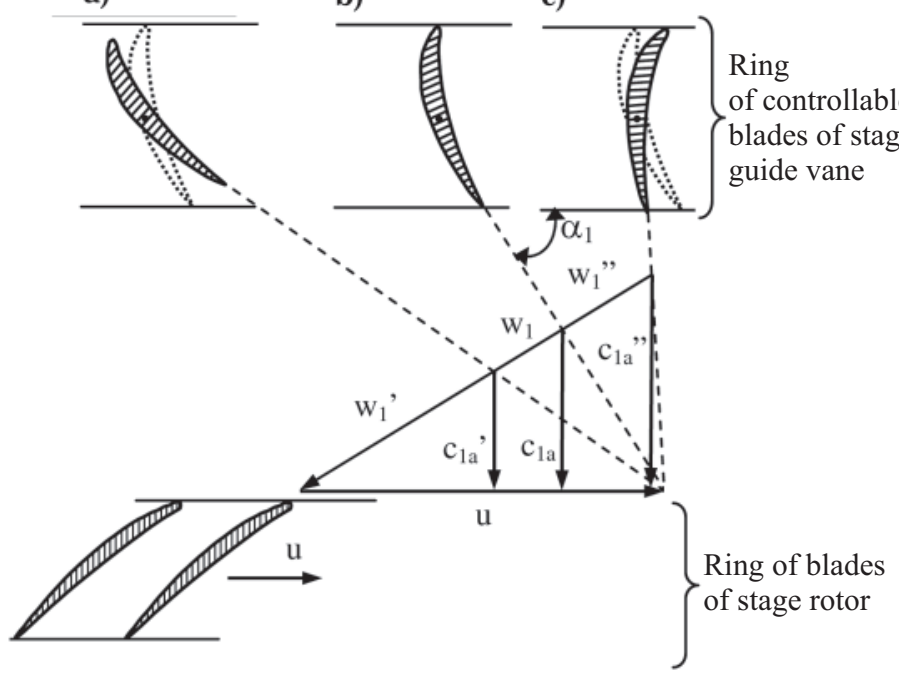

Fig. 3. Essence of control of compressor's axial stage by changing the setting angle of blades of guide vane rings at changeable air flow velocity; a) decreased axial velocity, b) calculation axial velocity, c) increased axial velocity.

Application of a control system of geometry of flow passages to gas turbine engine of a given design type significantly influences unsteady processes. In multi-stage axial compressors of compression value exceeding $8 \div 10$ the design solution which ensures stable operation, is to apply a.o. controllable blades of inlet guide vane [4]. In Fig.4 are presented compressor characteristics of the engine fitted with controllable inlet guide vane, on which the lines of rotor acceleration and deceleration have been plotted.

The lines depicted on the characteristics represent the compressor's operation at three angular settings of inlet guide vane blades, $\alpha_{\mathrm{KW}}$, and the compressor rotational speed, $\mathrm{n}_{1}$, maintained constant.

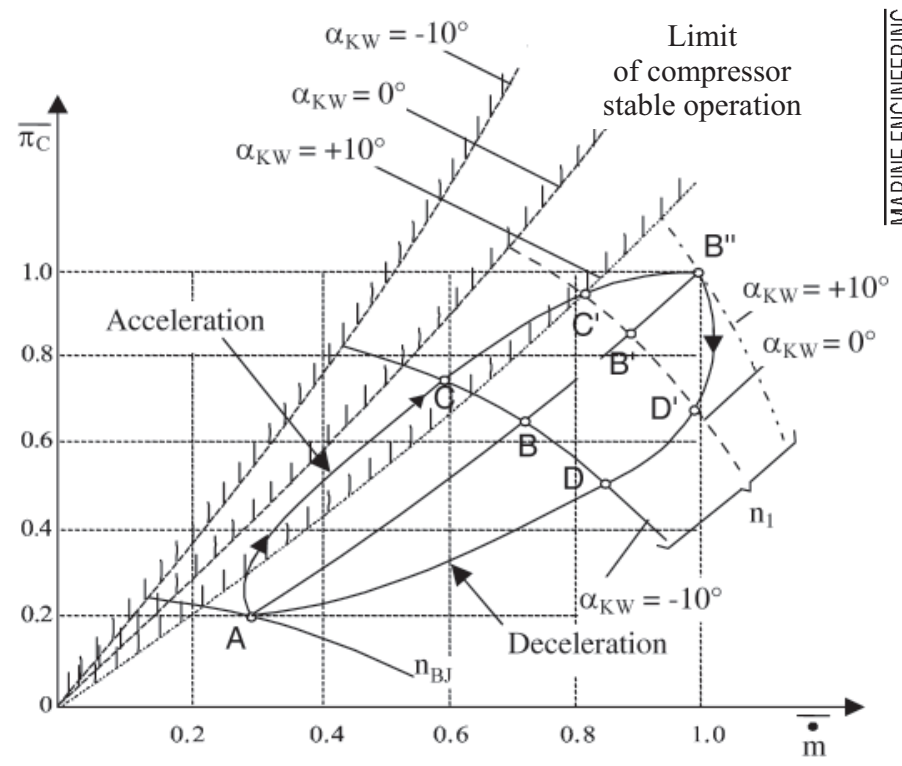

Fig. 4. Compressor characteristics plotted in the system of relative-value parameters - test stand measurements. Change of compressor operation range resulting from interaction of controllable inlet guide vane [5]; $A B B$ 'B" - points of co-operation

of the compressor with network in stable states; $A C C$ ' $B$ "- - points of co-operation

of the compressor with network during engine acceleration; $B$ 'D'DA-points of co-operation

of the compressor with network during engine deceleration .

From the run of the co-operation lines shown on the characteristics it can be concluded that in the engine fitted with controllable inlet guide vane, to control output parameters of its compressor at constant rotational speed of rotor unit, is possible.

The DR76 and DR77 triple-shaft engines operating within COGAG propulsion system installed on naval ships of „Tarantula" class, are equipped with such design solution of inlet guide vane. In Fig. 5 is presented the schematic diagram of such engine with indicated control cuts in its flow part.

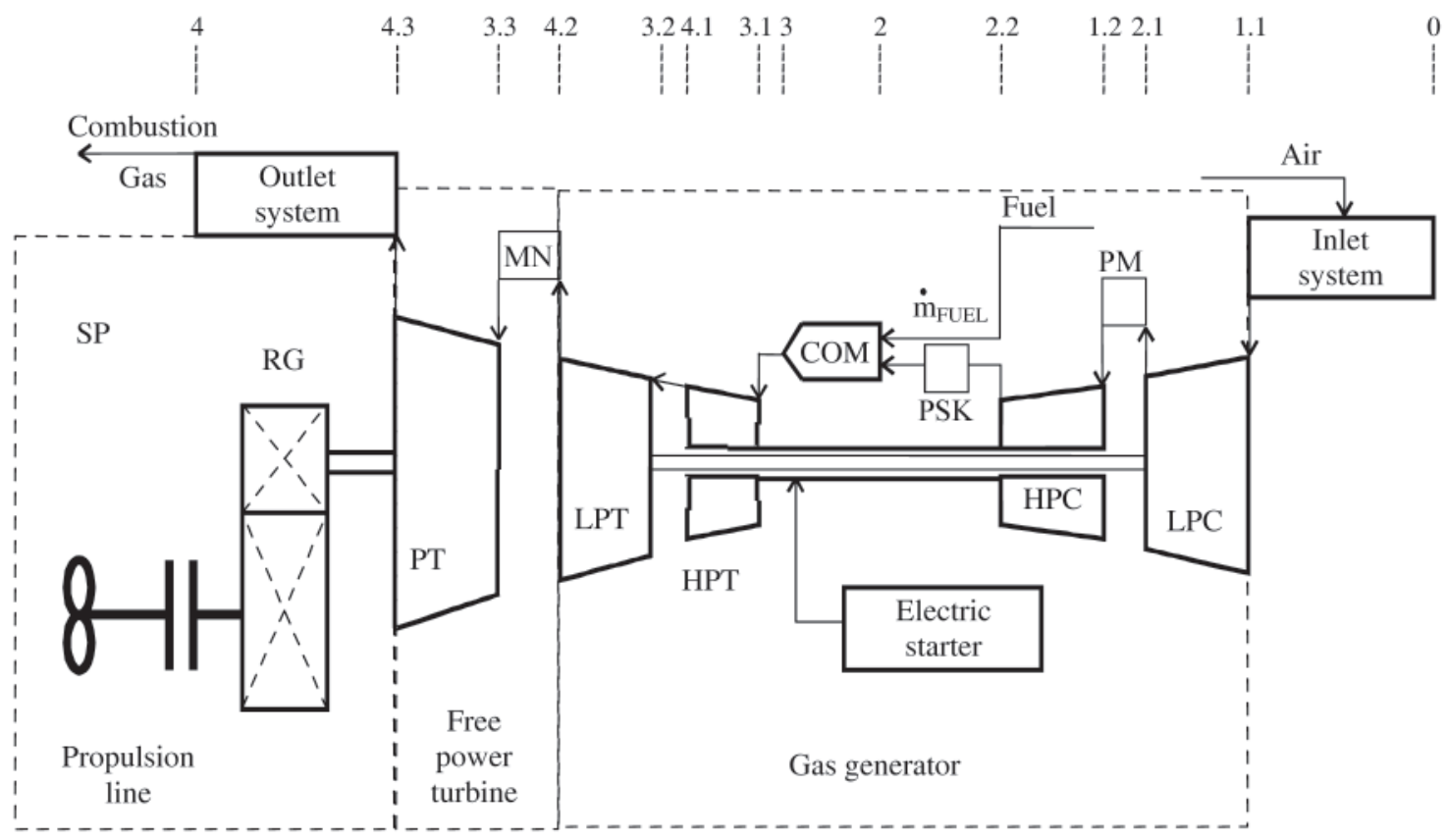

Fig. 5. Schematic diagram of ship gas turbine engine fitted with separate reversible propulsion turbine [6] 


\section{CONTROLLABLE GUIDE VANES OF FIRST STAGES OF COMPRESSOR}

In modern solutions of currently manufactured marine engines their compressors are fitted with controllable inlet guide vanes and controllable guide vanes of their first stages in order to ensure sufficient stable work margins. Such compressors are characterized by high compression values exceeding 20 . Of that type are the objects being a part of e.g. LM 2500 engines used for propelling the frigates of Oliver Hazard Perry class as well as TW-3 aircraft engines applied on Mi helicopters.

A characteristic feature of the sixteen-stage axial compressor of LM 2500 engine is the possibility of changing of setting of the outlet flow angles $\alpha_{1}$ of the blades of inlet guide vane and those of its first six stages in function of engine load. The solution prevents from unstable work of the compressor during fast realization of transient processes from one stable state to another. In the case of aircraft version of the engine such solution makes it possible to transit from "low gas" state to "full load" within only five seconds not going beyond stable operation zone.

In Fig. 6 are shown elements of the control system of angular setting of blades of particular guide vanes of the compressor of LM 2500 engine.

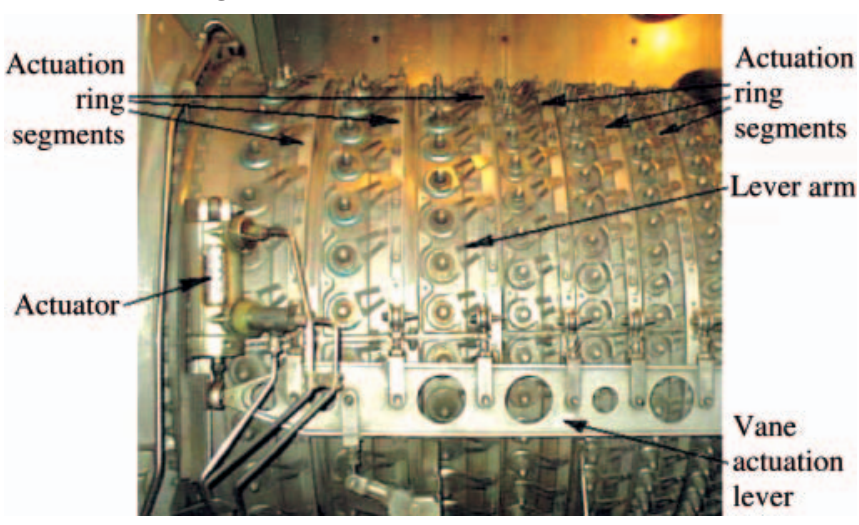

Fig. 6. Elements of the angular setting control system of blades of particular guide vanes of the LM 2500 engine's compressor

Fig. 7 presents the relation between the outlet flow angle, $\alpha_{1}$, of the controllable blade rings of guide vanes and the engine load represented by the rotational speed of gas generator's rotor, $\mathrm{n}_{\mathrm{zr}}$, reduced to the normal conditions (acc. ISA) at the inlet to the engine. The load control lever installed on the engine changes its position within the angular range $\lambda=39^{\circ} \div-3^{\circ}$, along with changing the gas generator's rotational speed within the range $\mathrm{n}_{\mathrm{zr}}=5000 \div 10000 \mathrm{rpm}$, which results in changes of the angular setting of air outlet from blades of inlet guide vane and guide vanes of particular compressor's stages within the range shown in Fig.7.

\section{MATHEMATICAL MODEL OF CHARACTERISTICS OF AXIAL COMPRESSOR WITH CONTROLLABLE BLADES OF INLET GUIDE VANE}

The problems of elaboration of sufficiently accurate mathematical models of axial compressors are associated with range of simplifying assumptions which determine accuracy of the numerical modelling of real object [8]. Simulating investigations require a.o. to convert the usual graphical form of compressor characteristics (Fig. 4) into functional one suitable for numerical calculations, i.e. to the following form :

$$
\pi_{\mathrm{s}}=\mathrm{f}\left(\dot{\mathrm{m}}_{\mathrm{zr}}, \mathrm{n}_{\mathrm{zr}}, \alpha_{\mathrm{KW}}\right)
$$
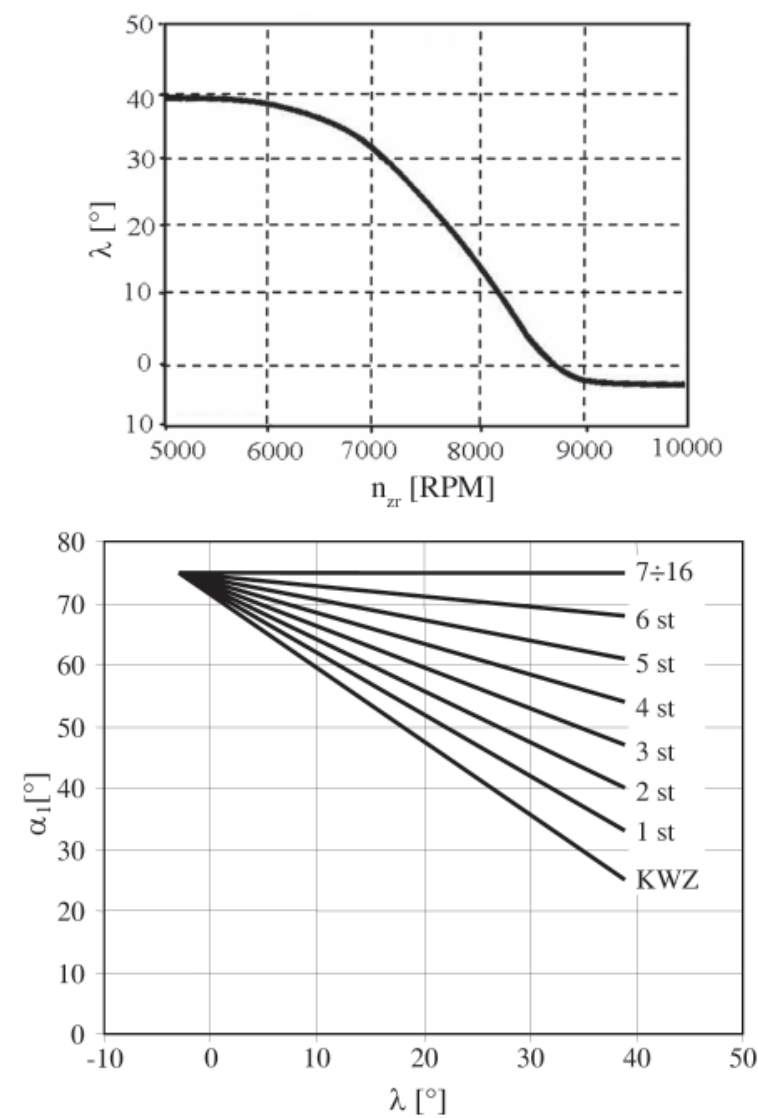

Fig. 7. Range of changes of the angle of air outlet from blades of rings of controllable guide vanes of compressor, $\alpha$ in function of the rotational speed $n_{z r}$ and the angular setting of load control lever, $\lambda$, of the LM 2500 engine $[7,8]$.

$$
\eta_{\mathrm{s}}=\mathrm{f}\left(\dot{\mathrm{m}}_{\mathrm{zr}}, \mathrm{n}_{\mathrm{zr}}, \alpha_{\mathrm{KW}}\right)
$$

The obtaining of an analytical form of the functional relations (1) and (2) which model real characteristics of compressor, at maintained minimum approximation error, is associated with the difficulties resulting from complex form of the functions. In the range of low rotational speeds, isodroms of the characteristics exhibit moderate slopes which correspond with $\pi_{\mathrm{s}} \approx$ idem, whereas in the range of high rotational speeds they show steep sections corresponding with $\dot{\mathrm{m}}_{\mathrm{zr}} \approx \mathrm{idem}$.

Hence it seems that the least squares method and multidimensional polynomial-based regression [3] can be an effective way for determining an analytical description of axial compressor operation, which guarantees that deviations of the model from reality would be contained within limits of measurement error.

The overall model of compressor is searched for by means of the set of regression equations which approximate its universal characteristics :

$$
\begin{gathered}
\pi_{\mathrm{s}}=\mathrm{a}_{0}+\mathrm{a}_{1} \dot{\mathrm{m}}_{\mathrm{zr}}+\mathrm{a}_{2}\left(\dot{\mathrm{m}}_{\mathrm{zr}}\right)^{2}+\mathrm{a}_{3} \mathrm{n}_{\mathrm{zr}}+\mathrm{a}_{4}\left(\mathrm{n}_{\mathrm{zr}}\right)^{2}+ \\
+\mathrm{a}_{5} \dot{\mathrm{m}}_{\mathrm{zr}} \mathrm{n}_{\mathrm{zr}}+\mathrm{a}_{6} \alpha_{\mathrm{KW}}+\mathrm{a}_{7}\left(\alpha_{\mathrm{KW}}\right)^{2}+ \\
+\mathrm{a}_{8} \dot{\mathrm{m}}_{\mathrm{zr}} \alpha_{\mathrm{KW}}+\mathrm{a}_{9} \mathrm{n}_{\mathrm{zr}} \alpha_{\mathrm{KW}} \\
\pi_{\mathrm{s}}=\mathrm{b}_{0}+\mathrm{b}_{1} \dot{\mathrm{m}}_{\mathrm{zr}}+\mathrm{b}_{2}\left(\dot{\mathrm{m}}_{\mathrm{zr}}\right)^{2}+\mathrm{b}_{3} \mathrm{n}_{\mathrm{zr}}+\mathrm{b}_{4}\left(\mathrm{n}_{\mathrm{zr}}\right)^{2}+ \\
+\mathrm{b}_{5} \dot{\mathrm{m}}_{\mathrm{zr}} \mathrm{n}_{\mathrm{zr}}+\mathrm{b}_{6} \alpha_{\mathrm{KW}}+\mathrm{b}_{7}\left(\alpha_{\mathrm{KW}}\right)^{2}+ \\
+\mathrm{b}_{8} \dot{\mathrm{m}}_{\mathrm{zr}} \alpha_{\mathrm{KW}}+\mathrm{b}_{9} \mathrm{n}_{\mathrm{zr}} \alpha_{\mathrm{KW}}
\end{gathered}
$$


Values of the regression coefficients $a_{i}, b_{i}$ are determined on the basis of the Gauss-Markov theorem when searching for minimum values of the functionals:

$$
\begin{gathered}
\mathrm{J}_{\pi_{\mathrm{s}}}\left(\mathrm{a}_{0}, \mathrm{a}_{1}, \mathrm{a}_{2}, \mathrm{a}_{3}, \mathrm{a}_{4}, \mathrm{a}_{5}, \mathrm{a}_{6}, \mathrm{a}_{7}, \mathrm{a}_{8}, \mathrm{a}_{9}\right)= \\
=\sum_{\mathrm{k}=1}^{\mathrm{n}}\left(\pi_{\mathrm{sk}}-\bar{\pi}_{\mathrm{sk}}\right)^{2} \\
\mathrm{~J}_{\pi_{\mathrm{s}}}\left(\mathrm{b}_{0}, \mathrm{~b}_{1}, \mathrm{~b}_{2}, \mathrm{~b}_{3}, \mathrm{~b}_{4}, \mathrm{~b}_{5}, \mathrm{~b}_{6}, \mathrm{~b}_{7}, \mathrm{~b}_{8}, \mathrm{~b}_{9}\right)= \\
=\sum_{\mathrm{k}=1}^{\mathrm{n}}\left(\eta_{\mathrm{sk}}-\bar{\eta}_{\mathrm{sk}}\right)^{2}
\end{gathered}
$$

They constitute sums of squares of deviations of the values obtained by using the model $\pi_{\mathrm{s}}, \eta_{\mathrm{s}}$ from real values $\pi_{\mathrm{s}}, \bar{\eta}_{\mathrm{s}}$. Adequacy of matching the mathematical description of characteristics of a given compressor and its real run can be assessed on the basis of the following factors :

a) value of the multi-dimensional correlation coefficient $\mathrm{R}$ expressed as follows :

$$
R=\frac{\sum_{n=1}^{N}\left[\left(Y_{n}-\bar{Y}_{r}\right)\left(\hat{Y}_{n}-\bar{Y}_{m}\right)\right]}{\sqrt{\sum_{n=1}^{N}\left(Y_{n}-\bar{Y}_{r}\right)^{2} \sum_{n=1}^{N}\left(\hat{Y}_{n}-\bar{Y}_{m}\right)^{2}}}
$$

b) value of the remainder variance $\bar{\sigma}^{2}$ expressed as follows :

$$
\tilde{\sigma}^{2}=\frac{1}{N-K-1} \sum_{n=1}^{N}\left(Y_{n}-\hat{Y}_{n}\right)^{2}
$$

Value of $\mathrm{R}$ should be as large as possible, and value of $\hat{\sigma}^{2}$ - as small as possible. It then speaks for an insignificant deviation of the model from reality.

The mathematical model of compressor can be improved by adding new terms or replacing the existing ones in the equations (3) and (4). Solution of the mathematical model of compressor consists in determining values of the coefficients in the elaborated regression equations.

The LP compressor of DR76 engine was used to confirm usefulness of the least squares method and multi-dimensional polynomial-based regression method for building the mathematical model of characteristics of the compressor with changeable flow passage geometry. In Fig.8 a part of the compressor model characteristics is presented for three angular settings of controllable inlet guide vane : $\alpha_{\mathrm{KW}}=-10^{\circ}, \alpha_{\mathrm{KW}}=0^{\circ}, \alpha_{\mathrm{KW}}=$

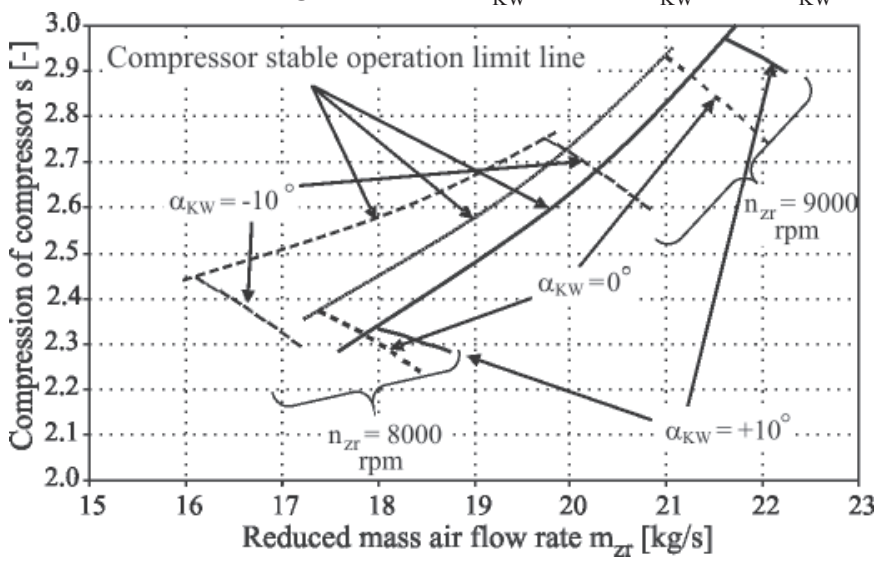

Fig. 8. Compressor model characteristics for changeable angles of setting of controllable blades of initial whirl guide vane; stable operation limit line for the angle of setting of controllable guide vane, $\alpha_{K W}=-10^{\circ}$, stable operation limit line for the angle of setting of controllable guide vane, $\alpha_{K W}=0^{\circ}$, stable operation limit line for the angle of setting of controllable guide vane, $\alpha_{K W}=+10^{\circ}$. $=+10^{\circ}$. Generally, for each angular position of guide vane blades the compressor characteristics take the form described by three values : of the rotational speed of compressor rotor, $\mathrm{n}_{\mathrm{zr}}$, of the mass air flow rate $\dot{\mathrm{m}}_{\mathrm{zr}}$, and the compressor compression $\pi_{\mathrm{s}}$. In Fig. 8 can be observed changes of the compressor operation range for two values of the reduced rotational speed of compressor, $\mathrm{n}_{\mathrm{zr}}=8000$ and $9000 \mathrm{rpm}$, in function of the angle of setting of controllable blades of initial whirl guide vane.

Values of the regression coefficients of the equations which approximate characteristics of the compressor in question are given in Tab. 1, and in Tab. 2 - values of statistical parameters showing degree of adequacy of values obtained from model investigations against experimental ones.

Tab. 1. Values of regression coefficients for particular equations.

\begin{tabular}{|c|c|c|c|c|}
\hline No. & $\begin{array}{c}\text { Regression } \\
\text { coefficient }\end{array}$ & Value & $\begin{array}{c}\text { Regression } \\
\text { coefficient }\end{array}$ & Value \\
\hline 1 & $\mathrm{a}_{0}$ & 2.099955 & $\mathrm{~b}_{0}$ & -0.583216 \\
\hline 2 & $\mathrm{a}_{1}$ & -0.312917 & $\mathrm{~b}_{1}$ & -0.272626 \\
\hline 3 & $\mathrm{a}_{2}$ & -0.022847 & $\mathrm{~b}_{2}$ & -0.017450 \\
\hline 4 & $\mathrm{a}_{3}$ & 0.000047 & $\mathrm{~b}_{3}$ & 0.000976 \\
\hline 5 & $\mathrm{a}_{4}$ & 0.000000 & $\mathrm{~b}_{4}$ & 0.000000 \\
\hline 6 & $\mathrm{a}_{5}$ & 0.000115 & $\mathrm{~b}_{5}$ & 0.000113 \\
\hline 7 & $\mathrm{a}_{6}$ & 0.059954 & $\mathrm{~b}_{6}$ & 0.068760 \\
\hline 8 & $\mathrm{a}_{7}$ & -0.003556 & $\mathrm{~b}_{7}$ & 0.000929 \\
\hline 9 & $\mathrm{a}_{8}$ & 0.016743 & $\mathrm{~b}_{8}$ & 0.009397 \\
\hline 10 & $\mathrm{a}_{9}$ & -0.000038 & $\mathrm{~b}_{9}$ & -0.000032 \\
\hline
\end{tabular}

Tab. 2. Degree of adequacy between the model and real object

\begin{tabular}{|c|c|c|c|}
\hline No. & Characteristics & $\mathrm{R}$ & $\hat{\sigma}^{2}$ \\
\hline 1 & $\pi_{\mathrm{s}}=\mathrm{f}\left(\dot{\mathrm{m}}_{\mathrm{zr}}, \mathrm{n}_{\mathrm{zr}}, \alpha_{\mathrm{KW}}\right)$ & 0.99939 & 0.00628 \\
\hline 2 & $\eta_{\mathrm{s}}=\mathrm{f}\left(\dot{\mathrm{m}}_{\mathrm{zr}}, \mathrm{n}_{\mathrm{zr}}, \alpha_{\mathrm{KW}}\right)$ & 0.99782 & 0.00298 \\
\hline
\end{tabular}

\section{CONCLUSIONS}

The presented mathematical model of axial compressor working in the gas turbine engine system makes it possible to numerically investigate the gas-dynamic processes taking place in its flow passages.

The changeable setting angles of blades of controllable guide vanes of particular compression stages, taken into account in the model, significantly widens possible identification of unserviceability states in the system of flow passage geometry control.

Simulative investigations of gas-dynamic processes taking place in the compressor in the conditions of introduced changes in set-up values of the input quantities of the presented model, make it possible to determine the diagnostic relations „defect-symptom” used for assessing technical states of gas-turbine engines.

\section{NOMENCLATURE}

\footnotetext{
$\alpha_{1} \quad$ - angle of air flow off blades of guide vane ring

$\alpha_{\mathrm{KW}} \quad$ - setting angle of controllable blades of guide vanes

$\beta_{1}, \beta_{2} \quad$ - angle of air inlet to and outlet off rotor blades, respectively

$c_{a} \quad-$ axial component of absolute flow velocity
} (1)

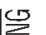
層 居 ப. 


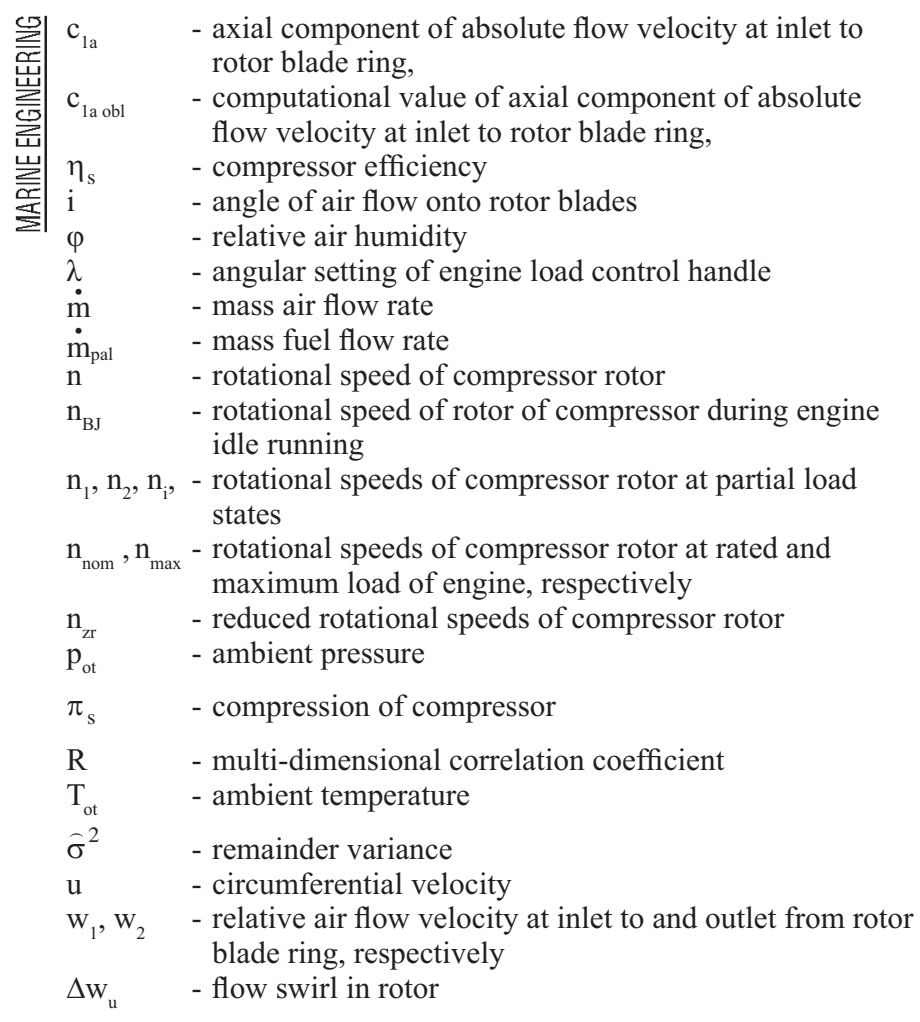

\section{Abbreviations and indices:}

$a, b . \quad$ - coefficients of regression equation $(i=0 \ldots 9)$

COGAG - Combination Gas-turbine and Gas-turbine propulsion system

$\mathrm{k} \quad$ - number of regression function coefficient

KS - combustion chamber

MN - space between propulsion turbine and LP turbine of engine

$\mathrm{n} \quad$ - number of measurement $(\mathrm{n}=1 \ldots \mathrm{N})$

$\mathrm{N} \quad$ - set of measurement points

PM - space between compressors

PR - reduction transmission gear

PSK - space between HP compressor and combustion chamber

$\mathrm{S}$ - compressor

$\mathrm{SN} \quad$ - screw propeller

SNC - low pressure (LP) compressor

SWC - high pressure (HP) compressor

TN - propulsion turbine

TNC - low pressure (LP) turbine

TWC - high pressure (HP) turbine

$Y_{n} \quad-$ real value at the instant of $n$-th measurement

$\hat{\mathrm{Y}}_{\mathrm{n}}^{\mathrm{n}} \quad$ - value calculated from model at the instant of $n$-th measurement

$\overline{\mathrm{Y}}_{\mathrm{r}} \quad$ - real arithmetic mean value

$\overline{\mathrm{Y}}_{\mathrm{m}} \quad$ - arithmetic mean value calculated from model

\section{BIBLIOGRAPHY}

1. Balicki W., Szczeciński St.: Diagnostics of aircraft gas turbine engines (in Polish). Published by Library of Institute of Aeronautics, Warszawa, 1997

2. Charchalis A.: Diagnostics of marine gas turbine engines (in Polish). Published by Polish Naval University, Gdynia 1991

3. Ćwik B., Szczeciński St.: Modelling the characteristics of radial compressor supercharging gas turbine engine (in Polish). Bulletin of Military Technical Academy (WAT), no. 3-4, vol. XLIV, Warszawa, 1995

4. Dżygadło Z. et al.: Rotor units of gas turbine engines (in Polish). Transport and Telecommunication Publishing House (WKiŁ), Warszawa, 1982

5. Korczewski Z.: A method for diagnosing flow part of marine gas turbine engine in service (in Polish). Polish Naval University. Doctoral thesis, Gdynia 1992

6. Korczewski Z.: Identification of gas-dynamic processes in compressor unit of marine gas turbine engine for diagnostics purposes (in Polish). Polish Naval University. Ass.Prof. qualifying dissertation, Gdynia, 1998

7. Korczewski Z., Wirkowski P.: Modelling gas-dynamic processes within turbine engines' compressors with variable geometry of flow duct. $4^{\text {th }}$ International Scientifical-Technical Conference “Explo-Diesel \& Gas Turbine '05”, Gdańsk-MiędzyzdrojeKopenhaga, Publ. by Gdańsk University of Technology, Gdańsk 2005

8. Marschal D.J., Muir D.E., Saravanamuttoo H.I.H.: Health Monitoring of Variable Geometry Gas Turbines for the Canadian Navy. The American Society of Mechanical Engineers 345 E.47 St., New York, N.Y.10017

9. Muszyński M., Orkisz M.: Modelling of gas turbine jet engines (in Polish). Published by Library of Institute of Aeronautics, Warszawa, 1997

10.Orkisz M., Stawarz S.: Modelling of characteristics of compressors of gas turbine engines (in Polish). Reports of Institute of Aeronautics, no.146, Warszawa, 1996

11.Pawlak W., Wiklik K., Morawski J.M.: Synthesis and analysiss of control systems of aircraft gas turbine engines by using computer simulation methods (in Polish). Published by Library of Institute of Aeronautics, Warszawa, 1996

12.Pieregudow W.: Least squares method and its application (in Polish). State Economical Publishers (PWE), Warszawa, 1967

13. Wirkowski P.: Double-rotor marine gas-turbine engine as an object of modeling (in Polish). $32^{\text {nd }}$ National Symposium „Diagnostyka Maszyn” (Diagnostics of Machines), Węgierska Górka, 2005.

\section{CONTACT WITH THE AUTHOR}

Paweł Wirkowski, Ms.C.

Mechanic-Electric Faculty,

Polish Naval University Śmidowicza 69

81-103 Gdynia, POLAND e-mail :p.wirkowski@amw.gdynia.pl

\section{Miscellanea}

\section{Days of Engineering}

On 23-25 November 2006, 37 th Days of Engineering was held on the occasion of $60^{\text {th }}$ Anniversary of Technical University of Szczecin, the oldest technical university of West Pomerania, as well as of many scientific technical societies of the town, namely : that of electricians, geodesists, mechanical engineers and technicians, water engineers and technicians as well as the Federation of Scientific Technical Societies NOT (Naczelna Organizacja Techniczna).

The jubilee was celebrated under the slogan :

\section{Youth and Engineering - a chance to developing the Town and Region}

which has had a very distinct meaning.

It was arranged by the following organizations :

$\Rightarrow$ the Federation of Scientific Technical Societies NOT, Szczecin

- Szczecin Division of the Polish Society of Electricians

Technical University of Szczecin

- The Society of Graduates from Technical University of Szczecin. 